\title{
Pengembangan pelayanan akupressur pada ibu di klinik pratama rawat inap Aisyiyah Pandaan-Pasuruan
}

\author{
Sri Mukhodim Faridah Hanum ${ }^{1 *}$, Hesty Widowati ${ }^{2}$, Widiarti ${ }^{3}$ \\ 1,2,3 Universitas Muhammadiyah Sidoarjo
}

\section{INFORMASI ARTIKEL:}

\section{Riwayat Artikel:}

Tanggal diterima: 25 Juni 2021

Tanggal direvisi: 20 Juni 2021

Tanggal dipublikasi: 30 Juni 2021

\section{Kata kunci:}

Kunjungan Pasien

Kesehatan ibu dan anak

Pelayanan Akupresur
Keyword :

Patient Visit

Mother and child health

Acupressure care

\section{ABSTRAK}

Latar Belakang : Pandemi Covid 19 membuat perubahan di segala bidang terutama pelayanan kesehatan. Klinik Pratama Rawat Inap Aisyiyah Pandaan adalah salah satu tempat pelayanan kesehatan yang terdampak Covid 19. Mitra PKM adalah bidan dan perawat Klinik Pratama Rawat Inap Aisyiyah Pandaan. Permasalahan mitra: Penurunan jumlah kunjungan yang cukup drastis akibat pandemi Covid 19. Berdasarkan permasalahan tersebut, tim pengabdian yang terdiri dari dosen kebidanan dan fisioterapi serta mahasiswa berusaha memberikan solusi untuk mengatasi permasalahan mitra, yaitu dengan penambahan jenis pelayanan berupa terapi komplementer akupresur pada ibu dan anak di Klinik Aisyiyah yang banyak dicari masyarakat. Tujuan PKM : menambah kompetensi SDM Klinik di bidang terapi komplementer akupresur untuk mendukung tambahan pelayanan baru di Klinik Aisyiyah Pandaan sehingga dapat meningkatkan kunjungan pasien. Metode yang digunakan dalam kegiatan ini yaitu dengan memberikan pelatihan akupresur pada bidan dan perawat Klinik Aisyiyah Pandaan. Materi pelatihan disampaikan oleh tim pengabdi tentang akupresur pada ibu khususnya untuk meningkatkan stamina dan produksi ASI selama nifas, massase bayi dan akupresur pada anak untuk berbagai keluhan ringan. Luaran dalam kegiatan ini adalah : 1) para bidan dan perawat memiliki pemahaman dan kompetensi pelayanan akupresur serta ada penambahan pelayanan baru di Klinik yaitu pelayanan akupresur pada ibu dan anak, 2) menjadi karya ilmiah yang dipublikasikan di jurnal nasional dan media massa.

Background: The COVID-19 pandemic has made changes in all fields, especially health services. Aisyiyah Pandaan Inpatient Primary Clinic is one of the health care facilities affected by Covid 19. PKM partners are midwives and nurses of Aisyiyah Pandaan Inpatient Primary Clinic. Partner problem: A drastic decrease of visits due to the Covid 19 pandemic. Based on these problems, the service team consisting of lecturers and students of midwifery and physiotherapy tried to provide a solution to overcome partner problems by adding additional services. The added service is the complementary acupressure therapy for mothers and children at the Aisyiyah Pandaan Clinic which is frequently sought by the public. The purpose of PKM: To increase the competence of clinical human resources in the field of complementary acupressure therapy to support additional new services at the Aisyiyah Pandaan Clinic to increase patient visits. The method used in this study is to provide acupressure training to midwives and nurses at the Aisyiyah Pandaan Clinic. The training materials were delivered by the service team about acupressure for mothers, especially to increase stamina and milk production during postpartum, infant massage, and acupressure for children for various minor complaints. The results of this study are: 1 ) midwives and nurses have an understanding and competence in acupressure service and there is a new service at the clinic, namely acupressure service for mothers and children, and 2) the study becomes scientific papers published in national journals and mass media 


\section{Pendahuluan}

Melihat permasalahan sosial yang muncul dalam masyarakat di wilayah Kecamatan Pandaan, khususnya di bidang kesehatan, ketersediaan Puskesmas sebagai satu-satunya fasilitas pelayanan kesehatan masyarakat saat itu, harus melayani masyarakat se-kecamatan Pandaan. Di sisi lain, Rumah Sakit Umum Daerah letaknya terlalu jauh, yaitu di Kecamatan Bangil (dengan jarak 14 kilometer).

Hal ini mendorong Muhammadiyah untuk merealisasikan rencana mendirikan Balai Pengobatan dan Rumah Bersalin di wilayah Kecamatan Pandaan. Oleh karena itu, pada tahun 2001, Persyarikatan Muhammadiyah terutama ibuibu yang tergabung dalam Aisyiyah, merealisasikan rencana tersebut dengan mendirikan Balai Pengobatan (BP) / Rumah Bersalin (RB) Aisyiyah Pandaan. Pada tahun 2009, BP/RB tersebut meningkat statusnya menjadi Klinik Rawat Inap Islam Aisyiyah Pandaan. Fasilitas pelayanan yang dimiliki klinik sejak berdiri hingga sekarang meliputi : Rawat Jalan poli umum dan IGD, Rawat Inap penyakit umum dan Persalinan, Poli Spesialis obgyn, USG, Laboratorium dan Gizi. Pelayanan kesehatan tersebut merupakan pelayanan kesehatan medis dasar yang sudah banyak pesaingnya. Saat ini keinginan masyarakat sudah bervariasi bahkan banyak yang kembali ke arah komplementer seperti akupuntur, akupressur, bekam, jamu dan lain sebagainya.

Berdasarkan data kunjungan pasien untuk pelayanan Kesehatan Ibu dan Anak (KIA) di klinik pratama dan rawat inap Islam Aisyiyah Pandaan, tahun 2020 sebesar 692 pasien, jumlah tersebut menurun dibandingkan tahun 2019 yaitu sebesar 965 pasien, dikarenakan situasi pandemi. Terjadinya penurunan jumlah kunjungan ini termasuk kunjungan kesehatan ibu dan anak.

Terkait hal tersebut maka dosen Universitas Muhammadiyah Sidoarjo (Umsida) bermitra dengan Klinik pratama dan rawat inap Islam Aisyiyah Pandaan dalam program pengabdian masyarakat dengan memberikan solusi berupa pendampingan pelayanan terapi akupresur pada ibu dan anak dengan memberikan pelatihan akupresur pada bidan dan perawat Klinik Aisyiah Pandaan untuk menambah kompetensi sehingga dapat memberikan pelayanan baru yaitu akupresur pada pasien ibu dan anak. Dalam situasi pandemi saat ini, sangat diperlukan upaya-upaya preventif untuk meningkatkan daya tahan tubuh. Salah satu upaya tersebut bisa dilakukan dengan terapi akupresur.

UU nomor 36 tahun 2009 menyebutkan pelayanan kesehatan tradisional terbagi menjadi pelayanan kesehatan tradisional keterampilan dan ramuan. Pelayanan kesehatan tradisional keterampilan dapat dilakukan secara manual seperti akupresur, dengan alat dan teknologi seperti akupunktur, khiropraksi, ataupun dengan olah pikiran/mental seperti husada, yoga, dan lain (Rini and Anhari Achadi, 2018).

Akupresur merupakan suatu cara penyembuhan yang menggunakan teknik penekanan dengan menggunakan jari-jari tangan ataupun dengan menggunakan alat bantu seperti stik kayu, dengan cara menekan titik-titik tertentu pada tubuh (titik-titik akupunktur) sebagai pengganti penusukan jarum pada penyembuhan akupunktur, untuk memperlancar aliran energi vital dalam tubuh. Tujuan penekanan pada titik-titik ini bermaksud agar aliran energi yang terhambat dapat dilancarkan kembali. Program pelayanan akupresur yaitu mengembangkan pelayanan kesehatan yang bertumpu pada kegiatan promotif dan preventif atau promosi dan pencegahan(Yudi Abdul Majid and Rini, 2018).

Akupresur tidak hanya efektif untuk mengobati berbagai macam penyakit, tetapi juga bermanfaat untuk mencegah penyakit, menjaga kesehatan dan memperpanjang usia. Selain itu aman dan mudah, tidak menyebabkan sakit, dan dapat diterapkan tampa memandang jenis kelamin dan usia. Akupresur bermanfaat untuk mencegah penyakit, menyembuhkan penyakit, rehabilitasi (pemulihan), dan peningkatan daya tahan tubuh (Dr. Heni Setyowati ER, S.Kp, 2018).

Hasil capaian kegiatan pengabdian masyarakat ini adalah agar peserta mendapat tambahan kompetensi sehingga dapat memberikan pelayanan akupresur pada pasien khususnya ibu nifas dan bayi yang sedang menjalani perawatan di Klinik Rawat Inap islam Aisyiyah Pandaan. 
Dengan adanya tenaga kesehatan yang memiliki kompetensi akupresur ini, diharapkan Klinik Rawat Inap Islam Aisyiyah Pandaan dapat membuka dan mengembangkan pelayanan kesehatan yang baru yaitu pelayanan akupresur pada ibu dan anak sehingga ke depan dapat meningkatkan jumlah kunjungan pasien ke klinik, mengingat terapi komplementer cukup banyak diminati masyarakat.

\section{Metode}

Metode pengabdian dilaksanakan dengan metode seminar, diskusi dan simulasi langsung secara berpasangan dengan tetap mematuhi protokol kesehatan. Para peserta terdiri dari tenaga perawat dan bidan di Klinik Rawat Inap islam Aisyiyah Pandaan sebanyak 7 orang. Dalam kegiatan pengabdian ini, peserta diajarkan teori akupresur, titik wajib akupresur di setiap meridian organ menurut Traditional Chinese medicine (TCM) dan prosedur akupresur pada ibu nifas untuk meningkatkan stamina dan produksi ASI dan massase bayi, serta diajarkan menggunakan aplikasi Acupoins Index untuk memudahkan menemukan titik akupresur yang dituju.

Titik akupresur pada ibu nifas yang diajarkan dalam pelatihan ini yaitu titik Taichong (LR3), Sanyinjiao (SP6), Xuehai (SP10), Zusanli (ST36), Neiguan (PC6), dan Hegu (LI4). Tim pengabdi menggunakan media powerpoint untuk menunjang pemaparan materi dan modul yang berisi petunjuk pelaksanaan tindakan akupresur. Pelatihan dilaksanakan selama 2 hari (12 jam) pada tanggal 29-30 Desember 2020.

Setelah penyampaian materi, tim pengabdi langsung melakukan evaluasi pemahaman tentang teori akupresur, kemudian penilaian praktik melakukan prosedur akupresur dilakukan pada hari terakhir pelatihan. Selain memberikan pelatihan akupresur, tim pengabdi juga memberikan media promosi pelayanan akupresur, berupa flyer agar dapat disebarluaskan melalui media sosial yang dimiliki Klinik.

\section{Hasil dan Pembahasan}

Kegiatan pengabdian pada masyarakat yang telah dilakukan ini merupakan implementasi tahap awal untuk mengatasi masalah mitra. Dengan adanya peningkatan kompetensi tenaga kesehatan (perawat dan bidan), sehingga ada tenaga medis yang terlatih untuk memberikan pelayanan komplementer akupresur yang lebih bermanfaat dan dibutuhkan pasien sehingga ke depan diharapkan dapat meningkatkan jumlah kunjungan ke Klinik.

Pelaksanaan pelatihan akupresur ini telah memberikan hasil adanya peningkatan pemahaman dan kompetensi peserta. Dengan bertambahnya kompetensi tersebut, Klinik Aiyiyah Pandaan dapat meningkatkan kuantitas dan kualitas jasa pelayanan. Evaluasi terhadap pemahaman dan keterampilan peserta dilakukan oleh tim pengabdi setelah melakukan pelatihan dan didapatkan hasil sebagai berikut.

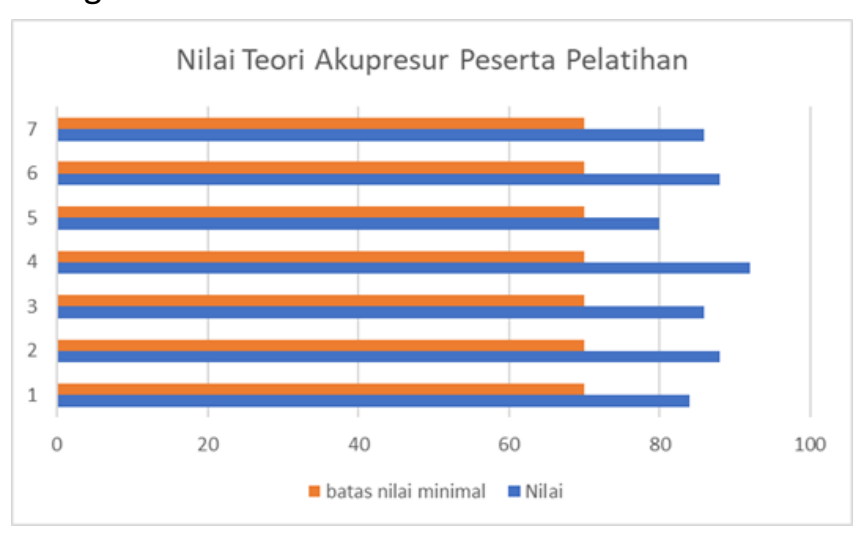

Gambar 1. Hasil Evaluasi Pemahaman Teori Akupresur Pada Ibu

Berdasarkan gambar 1 diketahui bahwa seluruh peserta mampu memahami teori akupresur dengan baik karena sudah memiliki dasar ilmu tentang tubuh manusia sehingga dapat menjawab pertanyaan yang disediakan tim pengabdi dengan baik. Peserta sangat antusias ketika mendengarkan materi akupresur karena teori yang dijelaskan merupakan hal yang baru bagi mereka. Evaluasi dilakukan langsung setelah pemberian materi dengan memberikan pertanyaan 25 pilihan ganda terkait materi yang telah diberikan.

Nilai Praktik Akupresur Peserta Pelatihan

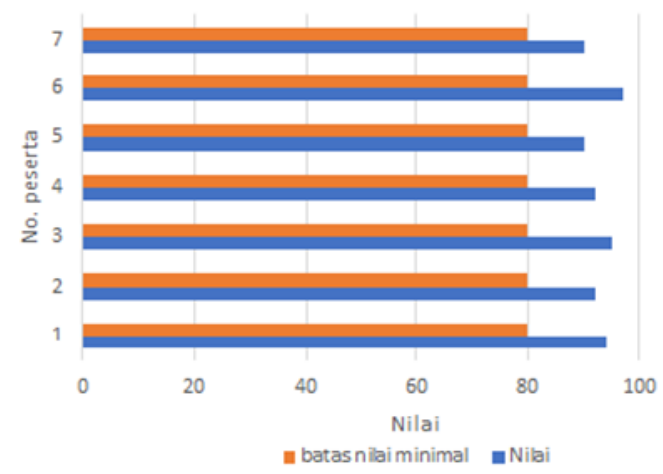

Gambar 2. Hasil Evaluasi Ketrampilan Akupresur Pada Ibu 
Pada gambar 2 menunjukkan bahwa seluruh peserta sudah kompeten dalam melakukan terapi akupresur pada ibu khususnya untuk meningkatkan stamina dan produksi ASI serta massase bayi. Setelah memahami teori dan dilakukan simulasi akupresur pada ibu, peserta diminta untuk mempraktekkan secara berpasangan sesuai petunjuk dalam modul. Penilaian praktik prosedur akupresur dilakukan pada hari berikutnya. Tim pengabdi menilai ketrampilan peserta pelatihan dengan menggunakan format penilaian praktik akupresur. Setiap langkah dinilai ketepatannya dengan skala penilaian 1-5. Angka tertinggi diberikan pada peserta jika dapat melakukan tindakan sesuai prosedur secara mandiri atau tanpa bantuan. Total nilai minimal peserta dinyatakan kompeten adalah 80 .

Respon mitra sangat positif dengan kegiatan pengabdian ini. Manfaat mengikuti pelatihan ini sudah bisa dirasakan secara pribadi oleh para peserta karena dapat diterapkan secara mandiri untuk diri sendiri dan keluarga. Untuk selanjutnya, pasien yang datang ke Klinik juga dapat merasakan manfaatnya. Titik Akupresur yang dipraktikkan dalam pelatihan ini, secara khusus bertujuan untuk meningkatkan stamina ibu nifas dan produksi ASI pada ibu nifas.

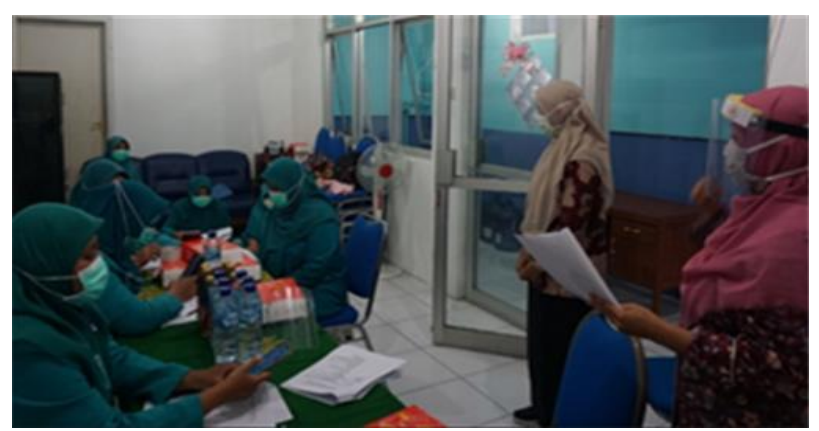

Gambar 3. Tim Pengabdi menjelaskan teori akupresur pada peserta

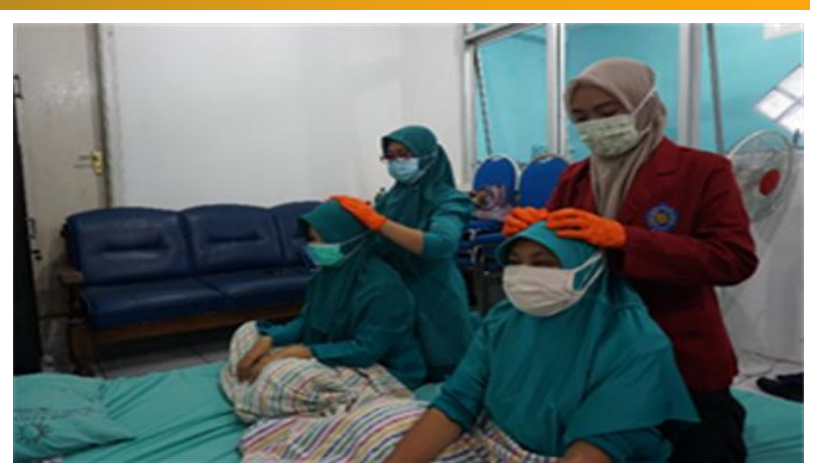

Gambar 4. Simulasi praktik akupresur untuk meningkatkan stamina

Salah satu tindakan untuk meningkatkan produksi ASI adalah dengan akupresur. Akupresur merupakan upaya penyembuhan yang berasal dari daerah timur dengan menggunakan massage titik tertentu dalam tubuh yaitu garis meridian atau aliran energi untuk mengurangi nyeri atau memperbaiki fungsi organ. Selain itu, akupresur adalah salah satu teknik pemijatan yang mudah dipelajari dan aman serta efektif digunakan sejak ratusan tahun (Saniyati Cholifah, Heni Setyowati ER, 2018).

Akupresur adalah salah satu bentuk terapi komplementer. Terapi komplementer adalah penggunaan terapi tradisional ke dalam pengobatan modern atau bisa dikatakan terapi tradisional yang digabungkan dalam pengobatan modern. Terapi komplementer yang ada menjadi salah satu pilihan pengobatan masyarakat. Di berbagai tempat pelayanan kesehatan tidak sedikit klien bertanya tentang terapi komplementer atau alternatif pada petugas kesehatan. Hal ini terjadi karena klien ingin mendapatkan pelayanan yang sesuai dengan pilihannya, selain itu, adanya reaksi efek samping dari pengobatan konvensional yang diterima menyebabkan memilih terapi komplementer. Oleh karena itu, dapat menjadi peluang bagi perawat atau tenaga kesehatan lainnya untuk berperan memberikan terapi komplementer. Minat masyarakat Indonesia terhadap terapi komplementer ataupun yang masih tradisional mulai meningkat (Widyastuti, 2018).

Akupresur sudah terbukti aman dan banyak manfaatnya. Pelayanan akupresur dapat diberikan sebagai upaya preventif dan promotif untuk memelihara dan meningkatkan status kesehatan 
serta mencegah dan mengatasi gangguan kesehatan ringan secara mandiri oleh individu, keluarga, maupun kelompok dan masyarakat. Oleh karena itu, tenaga kesehatan dapat mengambil peran sebagai terapis maupun konselor, sehingga dapat menjadi peluang usaha yang dapat dijalankan di Klinik maupun praktik mandiri mengingat kebutuhan masyarakat yang meningkat.

Dalam kegiatan pengabdian masyarakat ini, tim pengabdi tidak hanya melatih para perawat dan bidan di Klinik Aisyiah Pandaan agar kompeten dapam melakukan pelayanan akupresur tetapi juga memfasilitasi dalam pembuatan media promosi pelayanan akupresur berupa flyer. Setelah memiliki tenaga yang kompeten dalam terapi akupresur, diharapkan Klinik mempersiapkan segala sesuatu yang dibutuhkan dalam pembukaan pelayanan kesehatan baru yaitu pelayanan akupresur salah satunya adalah media promosi. Flyer yang telah dibuatkan dapat disebarluaskan melalui media sosial untuk memperkenalkan kepada masyarakat luas tentang pelayanan kesehatan baru di Klinik Aisyiyah Pandaan jika sarana dan prasarana udah siap.

Pada era digital, media sosial saat ini telah menjadi trend dalam komunikasi pemasaran. Media sosial adalah sebuah media online, dengan para penggunanya bisa dengan mudah berpartisipasi, berbagi, dan menciptakan isi meliputi blog, jejaring sosial, wiki, forum dan dunia virtual. Promosi menggunakan media sosial memiliki kelebihan yaitu mudah diakses dimana saja dan kapan saja, karena setiap hari handphone dibawa kemana-mana dan selalu up date. Selain itu, promosi tidak berbayar dan lebih luas untuk market sharenya. Jadi promosi melalui media sosial itu sangat efektif dikalangan masyarakat (Purbohastuti, 2017).

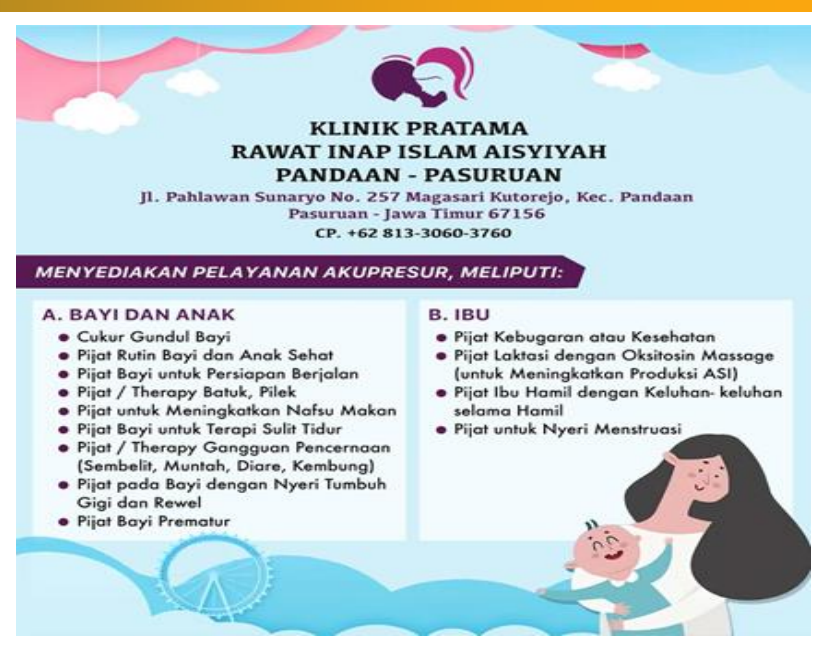

Gambar 5. Flyer Promosi Pelayanan Akupresur di Klinik Aisyiyah Pandaan

\section{Simpulan}

Kegiatan Pengabdian kepada masyarakat di Klinik Rawat Inap Islam Aisyiyah Pandaan berjalan dengan baik dan lancar. Pengetahuan dan ketrampilan peserta dalam akupresur meningkat setelah mengikuti pelatihan. Tenaga perawat dan bidan yang telah mengikuti pelatihan akupresur sudah dinyatakan kompeten dalam pelayanan akupresur pada ibu dan anak berdasarkan hasil penilaian tim pengabdi. Pelayanan akupresur merupakan terapi komplementer yang bisa dijadikan peluang bisnis terutama saat pandemi saat ini dengan mengoptimalkan media social sebagai media promosi secara online.

\section{Ucapan terima kasih}

Penulis mengucapkan terimakasih kepada Direktorat Riset dan Pengabdian Kepada Masyarakat Universitas Muhammadiyah Sidoarjo atas dukungan dana terhadap kegiatan pengabdian tersebut. 


\section{Daftar Pustaka}

Dr. Heni Setyowati ER, S.Kp, M. K. 2018. Akupresur untuk Kesehatan Wanita Berbasis Hasil Penelitian. Magelang: Unimma Press.

Purbohastuti, A. . 2017. Vol. 12, No. 2, Oktober 2017. Tirtayasa Ekonomika. 12(2), pp. 212231.

Rini, S. O. D. P. and Anhari Achadi. 2018. Program Pelayanan Akupresure Di Puskesmas Di Kota Jakarta Selatan Tahun 2018. pp. 1-18. Available at: http://journal.fkm.ui.ac.id/ihpa/article/downl oadSuppFile/2431/940.
Saniyati Cholifah, Heni Setyowati ER, R. M. 2018 Akupresur Pada Ibu Menyusui Meningkatkan Kecukupan Asupan Asi Bayi Di Kecamatan Mungkid Tahun 2014, Jurnal Keperawatan Maternitas.

Widyastuti. 2018. Terapi Komplementer Dalam Keperawatan. Jurnal Keperawatan Indonesia. doi: 10.7454/jki.v12i1.200.

Yudi Abdul Majid and Rini, P. S. 2018. Terapi Akupresur Memberikan Rasa Tenang dan Nyaman serta Mampu Menurunkan Tekanan Darah Lansia. Jurnal Aisyah: Jurnal Ilmu Kesehatan, 1(1), pp. 79-86. doi: 10.30604/jika.v1i1.11. 